\title{
LAS NORMAS EN LA PRODUCCIÓN DEL ESPACIO ESCOLAR
}

\author{
Soledad Roldán (Universidad Nacional del Comahue)* \\ soleroldan@yahoo.com.ar
}

Recibido: 29/07/2011 Aceptado: 26/10/2011

\begin{abstract}
Resumen
Este artículo muestra algunos avances de una tesis doctoral en curso. El mismo aborda los nuevos significados que adoptan regulaciones escolares tradicionales como las relativas a la vestimenta. Si bien éstas tuvieron una fuerte impronta en la fundación del sistema educativo argentino, entendemos que actualmente se reeditan con matices que producen nuevas formas de comunidad. En nuestro análisis las normas se conciben como productoras del espacio escolar y sus fronteras. En este sentido, intentaremos mostrar que frente a la crisis de los lazos sociales tradicionales, la vestimenta puede ser una forma de producir anclajes y pone en evidencia la potencia de la escuela en la construcción de nuevos modos de asociación que se fundan muchas veces en nuevos modos de cerrazón y de exclusión y, muchas otras, habilitan el paso hacia otros escenarios y futuros posibles. Este planteo pone en juego la pregunta por 'lo común' a la que la escuela moderna respondió a través de la homogeneización.
\end{abstract}

\section{Palabras clave}

Normas Escolares - Nivel Medio - Vestimenta - Espacios comunes.

\section{Abstract}

This article shows some progress of a PhD thesis on course. It discusses the new meanings that traditional school regulations adopt, such as those concerning on clothing. Although these regulations had a hard mark on the foundation of the Argentine educational system, we understand that they are now reissued with shades that produce new forms of community. In our analysis rules are considered as producers of school space and its borders. In this sense, we attempt to show that addressing the crisis of traditional social ties, clothing may be a way to produce anchors and highlights the power of the school in the production of new forms of association which are often based on

* Profesora en Ciencias de la Educación. Doctoranda en Ciencias Sociales (6 $6^{a}$ cohorte 2007-2009). FLACSO Argentina. 
new modes of closure and exclusion, and many others, enable the transition to other scenarios and possible futures. This analysis compromises the question about 'common order', to which modern school responded through homogenization.

\section{Key words}

School Regulations - Secondary School - Clothing - Space- Community.

\section{Introducción}

Este trabajo surge en el marco de una tesis doctoral en curso: "La producción de fronteras en la configuración del orden escolar. El nivel medio en Neuquén". En la misma partimos de la idea de que el orden escolar se construye en la encrucijada entre las dimensiones de la política y lo político (Mouffe, 2007), que implican una definición del 'afuera' escolar y una particular relación con él.

Entendemos las normas en tanto mecanismos de tramitación de los conflictos y construcción de fronteras entre el 'adentro' y el 'afuera' escolar. En este sentido, el análisis de las normas es central para comprender la producción del espacio escolar.

En un trabajo anterior (Litichever, Machado, Núñez, Roldan \& Stagno, 2008), exploramos las diferencias entre aquellos reglamentos de convivencia que continuaban regulando cuestiones propias de la escuela de principios del siglo XX (puntualidad, vestimenta, higiene) y aquellos que incorporaban nuevas regulaciones sensibles a problemáticas actuales (violencia, robos, etc.) que denominamos neotrasgresiones.

Sin embargo, en esta oportunidad quisiéramos concentrarnos en las regulaciones tradicionales y los nuevos significados que se articulan a ellas, subvirtiendo los sentidos conocidos. Sentidos que parecerían haber desaparecido o haber perdido vigencia. Además, mostraremos que las cuestiones reguladas tradicionalmente (vestimenta) se han tornado un modo de tramitación de problemáticas actuales.

Los avances aquí esbozados surgen del análisis de reglamentos de convivencia, encuestas y entrevistas (1) realizadas en seis escuelas de nivel medio de la provincia de Neuquén, durante el año 2006 (2). La vestimenta y el aspecto/presentación personal aparecen -en algunas escuelas- con una recurrencia que es llamativa en un contexto en que los debates académicos y políticas educativas a nivel nacional parecieran avanzar en la ponderación de otros elementos para pensar la convivencia. Nuestra hipótesis es que estas regulaciones representan estrategias conocidas que adoptan las escuelas para la tramitación de ciertas problemáticas frente a la falta de revisión de los marcos normativos vigentes en la provincia de Neuquén. 
Por otra parte, entendemos que los nuevos fines y sentidos con que se apela a estas normas están en estrecha relación con la construcción de nuevas formas de 'comunidad', y que evidencian la necesidad de recuperar la pregunta por lo común frente a la destrucción de los lazos tradicionales en los que la escuela tenía una fuerte responsabilidad.

\section{La convivencia en Neuquén: acciones y omisiones en la producción de un vacío.}

En el siglo XIX y parte del siglo XX, la escuela fue una de las herramientas privilegiadas que utilizaron los Estados para la 'invención de la Nación' (Hobsbawm y Ranger, 1984, citado en Kriger, 2010, p. 52). Las normas jugaron un fuerte papel en la regulación de los sujetos pero también en su incorporación a un 'Nosotros' nacional. La tarea central fue la formación del ciudadano como sujeto forjado en torno a la ley (Duschatzky \& Birgin, 2007).

La crisis de esta concepción ligada -entre otras cosas- al debilitamiento del lazo social moderno, ha puesto en debate los marcos normativos de las instituciones de socialización. En el caso del nivel medio, el debate se vincula además al proceso de masificación del nivel y las consiguientes demandas de inclusión hacia la escuela que ponen en tensión las pautas culturales transmitidas por ella.

En nuestro país, diversas instancias dieron lugar a la revisión de la disciplina escolar, una de las cuales -quizás la más fuerte- tuvo lugar en el período de transición democrática. La amplia tradición contestataria (3) que caracteriza a Neuquén tuvo uno de sus hitos fundacionales en el accionar de los movimientos de derechos humanos en este período. Sin embargo, el impulso democratizador no logró concretarse en cambios normativos concretos.

A fines de la década del '90, la disciplina escolar cobró centralidad nuevamente, a partir de la configuración de discursos sobre la seguridad que vinculaban violencia, delito y pobreza, responsabilizando a las instituciones de socialización por la crisis de autoridad (Kessler \& Goldberg, 2000) y apuntando a los jóvenes como nueva 'amenaza' (Reguillo, 1997). En Neuquén este discurso se materializó en la política de seguridad implementada en los gobiernos de Jorge Sobisch (1991-1995/1999-2003/2003-2007), que representa un "nuevo" paradigma policial '...que postula al delincuente ex ante, violentando las mínimas garantías legales existentes.' (Lizárraga, 2008, p. 12).

Luego del 2001, en un contexto atravesado por una fuerte crisis de la representación política se concretaron, en algunas jurisdicciones, las intenciones de renovar los acuerdos de convivencia de las escuelas (Dussel, 2005).

El hecho de que ninguna de estas instancias se concretara en la provincia de Neuquén no es un dato aislado sino que se enmarca en la compleja relación que se ha instalado en la provincia respecto de 'la ley', atravesada por el 
histórico enfrentamiento entre el nivel central de gobierno y el gremio docente (ATEN) (4).

La ausencia de un Diseño curricular para el Nivel Medio y la consecuente proliferación de planes de estudio (5), da cuenta de esta actitud política del gobierno de la educación. Debattista (2004) plantea que mientras en algunos aspectos -especialmente los administrativos- el Consejo Provincial de Educación ha ejercido un control sobre las instituciones, en otros temas la política oficial ha adoptado la forma de dejar hacer: no censurar pero tampoco producir políticas concretas en algún sentido. Esto se conjuga con el accionar del gremio docente que ha rechazado los diversos marcos curriculares propuestos (como la Ley Federal) (6) y no ha producido alternativas al respecto.

La convivencia en el Nivel Medio neuquino continúa regulada por el Reglamento General para los Establecimientos de Enseñanza Secundaria, Normal y Especial (Decreto 150.073/43, texto ordenado en 1957) y la Disposición 407/85 de la Ex -Dirección Nacional de Educación Media, que esclarece los criterios para la aplicación de las sanciones estipuladas en el mencionado reglamento; proceso que aparecía en la norma originaria ligado a un fuerte sesgo autoritario. Tampoco se han producido medidas tendientes a la incorporación la Ley provincial 2302/99 de Protección Integral de la Niñez y la Adolescencia, cuyos principios tienen incidencia directa en la convivencia.

Podemos pensar el mapa de la normativa educativa provincial como un espacio sin demasiadas líneas directrices, lo que produce una situación que obstaculiza la relación de las escuelas con las normas. Por un lado, existe una proliferación de normas sobre el mismo tema -acreditación, asistencia-, elaboradas en un corto período de tiempo -por diversos rechazos y modificaciones- hace que se pierda claridad sobre los criterios normativos sobre los que se toman decisiones en las instituciones. Por otro lado, existe un vacío normativo en relación a la convivencia -ya que las normas aún vigentes han mostrado su caducidad en los hechos- que deja librada su construcción a las condiciones institucionales de cada escuela. Esto se puso en evidencia en el análisis sobre los reglamentos escolares, ya que los mismos presentan escasos patrones comunes respecto de la estructura, contenido, temas y alcances. Por otro lado, en los rasgos comunes no parece haber una incidencia contundente de las variables que suponíamos fundamentales en este sentido (modalidad de la escuela, tipo de gestión y población a la que atiende).

\section{La vestimenta: viejas regulaciones en la producción de nuevos espacios}

El abordaje de las normas respecto de la vestimenta no es nuevo y de hecho, es uno de los aspectos en los que se concretaron algunas tendencias pedagógicas vigentes en los inicios del sistema educativo argentino. Nos interesa aquí analizar el modo en que una regulación tradicional se articula a nuevos 
y viejos significantes produciendo nuevas fisonomías para el espacio escolar, respecto del afuera construido y de los puentes tendidos desde y hacia él.

El guardapolvo, en el caso de la escuela primaria, apareció en las primeras décadas del siglo XX y se mantuvo vigente apoyado en el discurso del igualitarismo. En este marco discursivo, la posibilidad de una igualdad abstracta y de ocultar las diferencias fue convocante para muchos inmigrantes y familias pobres (Dussel, 2003).

Otro de los grandes discursos que posibilitaron la emergencia del guardapolvo fue el higienismo que se consolidó a fines del siglo XIX. La higiene paso a ser considerada un cuerpo de saberes en la pelea contra el contagio y la enfermedad y 'los delantales debían ser... una protección contra el mundo exterior, una defensa puesta por la escuela para higienizar y limpiar a sus estudiantes' (Dussel, 2003, p. 23).

En el nivel medio, la vestimenta ha seguido un curso distinto:

(...) en Argentina, mientras que hasta 1984 los estudiantes secundarios usaban el guardapolvo blanco como uniforme en el caso de las mujeres y el saco blazer azul con pantalón gris en el caso de los varones, desde ese entonces se produjo una liberalización de los códigos de vestimenta, que ha convertido al tema en un terreno especialmente conflictivo en las relaciones entre adolescentes y adultos (...) (Dussel, 2005, p. 1115)

En el caso de los secundarios neuquinos, el guardapolvo ha sido utilizado por las mujeres pero en los varones la vestimenta no ha seguido ningún patrón. Si bien existieron exigencias respecto de la 'sobriedad', por lo menos hasta los años ' 80 , más tarde se flexibilizaría la vestimenta para los varones sin modificarse el uso del guardapolvo para las mujeres. Aproximadamente a fines de la década del '90 en la mayoría de las escuelas el guardapolvo -para las mujeres- se convirtió en una opción.

Como vemos en el cuadro de la página siguiente, las exigencias respecto del Aspecto Personal (que incluye la vestimenta) es bien distinto en cada escuela de la muestra.

Como podemos apreciar la exigencia no sigue un patrón que se corresponda, como podríamos suponer, con el tipo de gestión de la escuela o con la población a la que atiende. La diferencia entre las dos escuelas privadas es muy importante y algo similar ocurre entre las escuelas públicas. En la escuela 06 la exigencia se explica por el uso de uniforme -que no existe en el caso de la escuela 03-, sin embargo, no es una preocupación recurrente en las voces de los entrevistados/as, como si lo es en el caso las escuelas públicas 01 y 04.

En el caso de la escuela 01 -técnica- no existen normas formales en relación a la vestimenta sin embargo los alumnos del ciclo superior concurren a las clases vestidos con camisa y corbata y esta aparece -en encuestas y entrevistas- como una de las normas más exigidas. El argumento -de los/as 


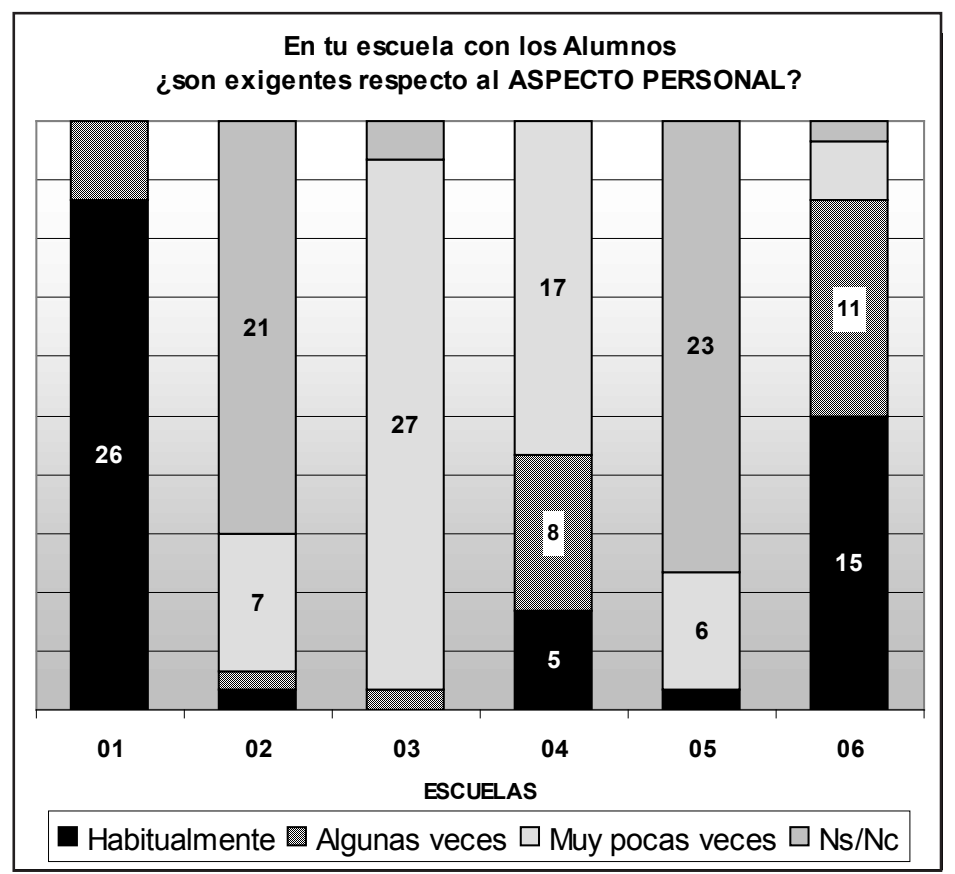

Fuente: Elaboración propia. Los resultados están expresados en valores nominales sobre una base de 30 encuestas.

que están a favor - es que constituye un hábito para el mundo del trabajo: “... yo tengo compañeros que están re convencidos que esa tiene que ser la forma. ¿Si? porque dicen después cuando van a buscar trabajo, les exigen que vayan bien vestidos, que hay que prepararlos" (Directora - Escuela 01).

Sin embargo, este argumento se sostiene sobre una visión estereotipada del mundo laboral en esta localidad. En las empresas petroleras y los laboratorios que suelen ser mencionados -por los/as entrevistados/as- como los posibles espacios de inserción laboral para los/as alumnos/as (7), este tipo de vestimenta se utiliza sólo en puestos gerenciales.

En otra de las escuelas públicas del interior de la provincia (04), este aspecto está fuertemente regulado en el reglamento de convivencia vigente, en el que son recurrentes las expresiones que remiten al aspecto personal: "se sugiere el uso de delantal para las niñas" y "se recomienda el cabello recogido (varones y niñas)". Además se establece que "[los alumnos] no podrán asistir con musculosa, short y calzado no adecuado" y que "la gorra/o sólo se podría usar en el patio, pero no dentro del establecimiento" (8). 
Si bien este reglamento es prácticamente desconocido para los/as estudiantes, sí aparece con fuerza en las entrevistas la exigencia por la vestimenta y la higiene, en relación a un reglamento que estaba en elaboración en ese momento (2006). El cambio más importante que éste incorporaría -y casi el único mencionado en las entrevistas- sería el uso de uniforme. Sin embargo, a diferencia e la escuela 01, aquí el debate no se da en torno a los sentidos del uniforme sino al modo de hacerlo operativo, esto es, cómo resolver la compra de los uniformes para la población rural pobre que asiste a la escuela. Si bien en la escuela 01 se menciona el factor monetario, aquí la preocupación es casi exclusivamente económica:

...y por todas estas cosas, siempre es bueno, caemos sobre el tema del uniforme, viste que yo no se si realmente todos los papás, este, van a estar en condiciones de comprar el uniforme, si bien se piensa que la cooperadora trabaje con, para que los alumnos que no puedan adquirir el uniforme, eh, lo tengan, pero también es muy difícil formar la cooperadora... (Profesor - Escuela 04)

...yo en un momento más que el uniforme, me pareció que la escuela quizás no da para uniforme porque la mayoría del pueblo en sí es un pueblo rural... entonces me parece a mí que lo que mejor podría haber sido es un guardapolvo. Un guardapolvo blanco, o el color que quieran, es más común, es más fácil de adquirir y es menos gasto... (Profesora - Escuela 04).

En el caso de la escuela 01 , la vestimenta aparece como un punto discutido aunque la postura hegemónica entre los adultos es la que sostiene el uso de la corbata. Sin embargo aquí los debates giran en torno a los significados que tiene la regulación sobre la vestimenta y a la idea de que sólo los alumnos/as sean objeto de la misma:

...yo tengo un problema con la corbata, para mí la corbata es símbolo de sumisión, de alguien que te agarra y te tiene... ¿viste? que te oprime (Directora - Escuela 01)

...cuando los otros dicen, no esto lo tenemos que cumplir todos y le tenemos que exigir a los chicos, me niego rotundamente, si no lo vamos, si no vamos a pensar en qué quiere decir la corbata y no nos vamos a reformular nosotros qué ponemos de valor en la corbata, no me voy a hacer cargo de esa corbata, esa corbata es de otro, no la mía, (risas)... (Profesora - Escuela 01).

Pero además hay expresiones de la directora y los/as profesores/as que dan cuenta de reiterados intentos de cambio que, por falta de acuerdos, no han prosperado.

La profesora dice que '...hace 18 años que me parece que es ridículo siempre lo he manifestado...', lo cual parece un tiempo prolongado para pro- 
ducir negociaciones y discusiones en pos de revisar la norma. Pero, incluso los/as que disienten con ésta, la consideran un símbolo de distinción positivo respecto de otras escuelas:

[E: ¿le parece que los alumnos en general cumplen las normas establecidas por el colegio?] $\mathrm{Si}, \mathrm{si}, \mathrm{y}$ en eso siento bastante orgullo porque bueno, es algo que se ah inculcado y se ha inculcado y es una de las escuelas que mejor vestidas viene y que mejor comportamiento tiene dentro de la escuela. (Profesor - Escuela 01).

...dentro del imaginario colectivo está "en la EPET se trabaja, en la EPET hay orden, en la EPET hay, este, disciplina”, como contraposición al laissez faire de la mayoría de los otros colegios, que eso si existe también... si? o de toda la cosa light que da todo lo mismo, que eso también existe' (Profesora Escuela 01)

...para mí tiene que ver a veces con un mandato familiar ¿Si? que es como que ser técnico te da más prestigio que ser perito mercantil o un bachiller... justo ese contrasentido parece que rechazan, no quieren esto [los alumnos], pero sin embargo lo siguen eligiendo y sin embargo siguen firmando viste el compromiso de la vestimenta... se sienten bien con respecto a otros colegios. Así vestidos parecen del CPEM [Centro Provincial de Educación Media] (9), porque algunos vienen con la rem- "no, no, nosotros somos de la EPET" (Directora - Escuela 01).

Aquí vemos emerger una lógica binaria y pendular que suele aparecer frente a la crisis de los sentidos, que construye posibilidades excluyentes: el 'orden' pérdido/en crisis o el laissez faire imperante en la actualidad. Aquí desaparece la pregunta por el contenido de las opciones en pugna y se hace evidente la imposibilidad de articulación (de nuevos significados), entendida como 'la práctica que establece una relación tal entre elementos, que la identidad de éstos resulta modificada como resultado de esa práctica' (Laclau \& Mouffe, 2004, p. 142-143).

La vestimenta aparece claramente como marca de identidad, como posibilidad de enlazar a los sujetos y de asegurar algunos sentidos comunes que, en otro momento, llevaron por nombre 'disciplina', 'orden'. La crítica a los modernos constreñimientos que imponía el 'hacerse parte de', ha dado paso a nuevas ataduras que recaen ahora sobre el sujeto individual. En este contexto, la vestimenta es una vieja estrategia que funciona en la producción de algunas ligazones seguras.

Podríamos pensar que frente a los diversos embates que ha sufrido la escuela -tanto desde las políticas de corte neoliberal como desde algunas posturas críticas- la vestimenta ligada en el 'imaginario colectivo' al orden, la disciplina y el trabajo, pone a los/as docentes que la resisten, en una tensión 
que implica despojarse de uno de los pocos elementos por el cual la escuela se vuelve visible y reconocida en la localidad. Aún más en un momento en el que abundan los imperativos que le exigen a la escuela sostener una relación con la comunidad que la circunda.

Grinberg (2008) plantea que la comunidad aparece en las 'sociedades del gerenciamiento' como un lugar no-político e incluso anti-político y la escuela ya no es la representante de lo público. En este contrato escuela-comunidad, la escuela debe tornarse una institución comunitaria y diferenciarse cada vez más de aquello que la constituyó en el siglo XIX: la educación como cosa de Estado. La escuela, cada escuela, desarticulada de las demás, se torna artífice de su destino y de su responsabilidad por él.

Es posible que este 'diferenciarse' opere como exigencia en la vestimenta, incluso en las escuelas públicas. Quizás, desligadas de su papel como representantes de lo público, construyen la relación con la comunidad -que aparece como su única salvaguarda- respondiendo a sus demandas sin mediaciones. Quizás la persistencia de regulaciones como ésta, simbolizan 'los restos del naufragio' (Caruso \& Dussel, 1996), las hilachas del discurso escolar moderno en su potencia por incorporar a los sujetos a formas de grupalidad centrales en la formación de la ciudadanía, en la ficción de los iguales (Duschatzky \& Corea, 2002) que implicaba la promesa -aunque no siempre se concretara- de inclusión de los sujetos en un escenario mayor, la promesa de 'ser parte de' un proyecto mayor (la Nación).

Los discursos críticos que supusieron la desigualdad como única opción para describir el espacio escolar, dejaron a la escuela sin nada 'entre manos' y la operación de respuesta ha sido en muchos casos el aferrarse a 'lo conocido' $y$, en consecuencia, producir marcas de exclusión, tanto más potentes en tanto operan como 'distinción' de otras escuelas, y no prometen una inclusión en terrenos más amplios que los de la propia 'comunidad'.

Lo interesante es cómo la fuerza de la exigencia se materializa en la interiorización que los alumnos han hecho de los significantes articulados a la vestimenta: vestimenta-exigencia.

[¿Por qué venís a esta escuela?] Me anoto mi mamá. Después empecé a venir y me quedo gustando porque son más exigentes. Si me anotaba a la otra quizás no iba a terminar tan bien como ahora porque yo era un desastre. En esta escuela son muy exigente y eso es bueno... por ejemplo con la vestimenta con la que tenés que venir acá... en otras escuela no lo exigen.... yo antes quería ir a la otra por mi compañeros, pero después acá me di cuenta que esta es mejor por todas las exigencias... (Alumno - Escuela 01).

En esta escuela, es llamativo el modo en que este tema atraviesa la voz de los alumnos, siendo una regulación que no aparece en el Acta Compromiso que firman a principio de año. En este sentido es interesante pensar en la potencia de la norma que, aunque de modo situacional, inscribe a los sujetos en 
un espacio común. Esta idea de que 'en algún lugar debe estar escrito que es obligatorio lo que hacemos habitualmente' (Siede 2007), emerge en las voces de los/as entrevistados/as:

Las normas generales ya están pautadas de antemano con respecto a los chicos... ellos aprenden a principio de año cuando se matriculan firman un acta de compromiso donde dice cómo debe ser la convivencia y cómo debe ser. Que a mí me parece que esta bien, porque ha/ o sea, no se si la heterogeneidad o la homogeneidad, pero se les pauta como tienen que venir vestidos tanto sea para los talleres o para los laboratorios, que deben traer y para cuando vengan no se les exigen ningún tipo de ropa, que vengan bien presentados nada más (Profesor - Escuela 01).

...por ejemplo si vos lees el coso de convivencia y de presentación del alumno que digan que tienen que venir todos los días con la corbata (Profesora - Escuela 01).

Este es un hábito que no ha adquirido su carácter legal aunque está institucionalizado hace muchos años. El cumplimiento efectivo de las normas no requiere de su legalidad. Esto hace que su legitimidad se construya, muchas veces, sobre la invisibilización de su carácter contingente, lo que dificulta su cuestionamiento.

Cuando se habla de convivencia en ambas escuelas (01 y 04), inmediatamente aparece la vestimenta, 'la corbata' o 'el uniforme' como ejemplo de las discusiones y también como objeto de la fascinación de algunos/as.

La vestimenta está ligada a la posibilidad -casi mágica- de tramitación de ciertas problemáticas, algunas más actuales como la violencia y otras ligadas a sentidos más tradicionales como la higiene.

Cuando se le pregunta al profesor acerca del momento inaugural de las normas, expresa:

...pero creo que la situación vino de cuando empezaron a verse que, vestidos en forma de, desastrosa porque era así y cuando empezaron a haber algunos hechos de violencia dentro de/ hubo que poner/ también en el momento que se empiece a cuestionar por qué si no está escrito, por qué tengo que hacerlo si no está en ningún lado. Entonces bueno, se formuló un cuadrito ahí de que hacen a las pautas generales para la/ de convivencia, de cómo deben ser los/ de cómo debe estar vestido. Mínimamente, tampoco tiene que ser a rajatabla (Profesor - Escuela 01).

[Respecto de las normas más importantes] y lo de la vestimenta, si, lo, lo indispensable para mi es el olor, porque en quinto no sabes lo que es el olor, por ahí ocho y media por ahí ya hay olor, o sea la higiene, es re importante, no se si tanto la vestimenta, porque bueno si ahora nos exigieran traer uniforme, estaría de acuerdo, no? Porque después empiezan esas diferencias de que 
uh que vos te vestís así, uh, o sos esto, sos lo otro, tenés plata, no tenés plata, sos pobre, entonces venimos con uniforme, venimos todos iguales y somos todos iguales... (Alumna - Escuela 04).

[Respecto de situaciones de discriminación] Tenemos un chico en el curso... por no ser higienizado, algo así, y los demás... "tenés olor a esto, tenés olor a todo". No le tendría que importar a nadie, si el chico sabe bien lo que tiene que hacer. El problema es él, si de ahí en más él toma la decisión de ponerse un desodorante o algo así, no le pueden echar en cara (Alumno - Escuela 04).

La vestimenta es la solución 'menos ruidosa' para temas que suelen tener mucha sonoridad: la discriminación, la desigualdad, la violencia. Los mismos, en estas escuelas, no producen cuestionamientos sino la necesidad de tramitar su resolución, aunque esto implique la invisibilización. La tramitación que habilitan estas regulaciones opera, muchas veces, inhabilitando la producción de dislocaciones al orden-siguiendo a Laclau (1990)- o quizás estas estrategias evidencian la necesidad de construcción de algún marco estructural-referencial -inexistente- el cual pueda ser dislocado.

El guardapolvo contribuyó fuertemente a la homogeneización de la población. Pero aún cuando en este caso, la vestimenta instauraba al espacio escolar como un espacio diferencial respecto del afuera, las identificaciones tenían que ver con 'lo escolar' en sentido amplio, como fundamento de una incorporación de los sujetos a una ciudadanía nacional. Las fronteras escolares establecían una distinción, que operaba para todos los que iban a la escuela, respecto de los 'otros', los de afuera. A esta distinción -que se sostiene hoy pero con otros matices- se le suman las distinciones de cada escuela.

En el caso de la escuela 04 el uniforme puede estar ligado a una versión renovada de ese higienismo, pero tanto en esta escuela como en la 01, el espacio escolar se vuelve discontinuo, no sólo respecto del afuera sino respecto de otras escuelas públicas. Aquí la vestimenta es una frontera que marca donde empieza 'esta' escuela -y puede indicar también 'donde termina'.

Entonces siempre esta abierto el portón y como hay chicos en contra turno que vienen a computación y como no llevan uniforme, sino vienen con ropa común, salen y entran como nada. Entonces por ahí se lle- ahora no tanto porque el hecho de que controlemos así es como que los tenés un poco (controlados) si, controlados (Profesora- Escuela04).

Porque si vos te parás en la puerta y no tienen una forma de identificarlo no sabés quién es quién. Porque ya viste, a veces no ves la circulación, yo porque más o menos estoy todas las tardes, hay caras que te son familiares, vos te vas acostumbrando, pero por ahí puede entrar alguien de otra escuela o de la calle y lo podes reconocer (Directora-Escuela 01). 
De forma sintética, nos parece interesante recuperar las normas que refieren a la puntualidad que son consideradas, por los/as alumnos/as de estas escuelas, una de las más exigidas pero también como una de las más importantes. Sin embargo, a diferencia de los sentidos que aparecen en torno a la vestimenta, los/as alumnos/as construyen -posiblemente a partir de argumentos aportados por los/as adultos/as- un sentido en torno a la puntualidad que excede las fronteras de la escuela en tiempo y espacio:

El día de mañana cuando estés trabajando no vas a llegar tarde porque es algo que aprendiste en la escuela secundaria ya que es algo que te lo exigían. ¿No? (Alumno - Escuela 01).

A: las mas importantes, bueno, la llegada tarde me parece importante, porque eso va creando cierta responsabilidad en nosotros, no?... después cuando salgamos de acá y tengamos que ir a, a seguir estudiando o ir a trabajar, no podemos llegar, eh, si entramos a las ocho, no podemos llegar ocho y cuarto, no podemos llegar tarde (Alumno - Escuela 04).

Es una norma que indica el comienzo de la escuela -'aquí y ahora empieza la escuela-', pero que marca la incorporación a un tiempo y un espacio 'no escolares' -el mundo laboral- en los que la escuela, sin embargo, tiene su continuidad, en las huellas que deja. Por el contrario, el único argumento -de los/as adultos/as- respecto de la vestimenta es que '[los alumnos] vienen vestidos de forma desastrosa/ de cualquier manera' o la imposibilidad de identificar cuando vienen en horario contra turno.

Quizás podamos pensar el recurso a la vestimenta como una estrategia que pretende materializar las fronteras de la escuela y, con esto, una forma de igualdad situada -a través de la homogeneidad-, allí donde las diferencias aparecen -en el discurso políticamente correcto- con una legitimidad inusitada. Sin embargo, así planteada, esta norma produce una clausura definitiva del espacio.

En las grietas de la 'pura diferencia'-que parece haber ordenado el discurso pedagógico de las últimas décadas-, en la imposibilidad de sutura que todo ordenamiento implica -incluso el de la pura diferencia-, el retorno del orden se materializa en una de sus viejas facetas: la homogeneidad pero ya sin 'ficción de igualdad'. La vestimenta es un privilegio de unos pocos, aquellos que se incorporan a una escuela en particular, a una 'comunidad', con unos códigos que distancian a los sujetos que la habitan de 'otros' que -aunque también vayan a la escuela (otra)- ya no comparten los mismos códigos.

En el caso de la escuela 04, 'los otros' -pobres, rurales, sucios- están dentro de la escuela, son los que imposibilitan la sutura del Nosotros y deben ser incorporados, borrando las marcas de origen. Este rasgo no es una contradicción en una época en que los sujetos han sido despojados de los lazos societales y las identificaciones que fundaron las instituciones modernas. Son 
formas de habitar el espacio en la era de la 'territorialidad desarraigada' (Ortiz, 1998 ) en la que conviven los flujos y el nomadismo junto con nuevos anhelos de cerrazón (Antelo, 2007).

Los nuevos sentidos articulados a la vestimenta se vinculan con otro rasgo que ha sido objeto de nuestro análisis: la familiaridad del espacio escolar en la producción de normas no formalizadas. La informalidad es una característica de las normas escolares tanto a nivel institucional como a nivel del sistema educativo neuquino. Este rasgo ha mostrado estar vinculado a la concepción de la escuela como espacio familiar, en el que el mutuo conocimiento de sus miembros -entre otros- torna innecesaria la recurrencia a normas.

Este es el caso de la escuela 03 -privada laica de la capital neuquina- en la que no existe regulación sobre la vestimenta, por el contrario, los/as alumnos/ as asisten a la escuela con distintos cortes y colores de pelo, piercings y las más variadas prendas como vestuario.

Esta característica al igual que la inexistencia de timbre de entrada y de salida, está enraizada en un ideal democrático-liberal que alimenta el proyecto de la escuela. La ausencia de regulaciones formales apunta a la 'voluntad' y 'responsabilidad' individual en la preservación del proyecto fundacional de la escuela, que se ve amenazado por el crecimiento de la matrícula que implica el ingreso de 'otros' que no lo conocen.

También en este caso el espacio se construye como discontinuidad con el afuera -desconocido- que pone en riesgo el sostenimiento del proyecto. Así se configura la fisonomía de 'la comunidad', cuya identidad se delinea por oposición a un 'afuera' y sus fronteras coinciden con los muros escolares. La diferencia es que, mientras en la escuela 04 , los 'otros' son parte de la escuela y son un problema a resolver a través de la vestimenta, en la escuela 03 los 'otros' son ubicados en el afuera que puja por desbordar los límites de la institución:

...es un porcentaje de los chicos que participa totalmente de la realidad exterior al colegio y esa realidad exterior al colegio, como decía antes, quieran o no, está inundando al colegio. Eh y y una de las puertitas más grandes abiertas a eso es el tema del número, ellos tienen que decidir si mantienen controlado el número de los cursos o no, ehh... parece muy reduccionista esto del tema del número pero... es crítico (Profesor - E03).

Esa decisión sobre el control del número de cursos, sobre el control de la diferencia, plantea al colegio una tensión con su propio proyecto. La idea es que si 'los de afuera' ingresan se diluye un proyecto que no precisa -entre los conocidos- ser explicitado y si se le niega el ingreso, el proyecto se niega a sí mismo en sus principios democráticos, de libre expresión, libre ingreso, respeto por las diferencias, no discriminación -proclamados en el reglamento-. 


\section{Al decir de Sennett:}

La imagen de la comunidad ha sido purificada de todo lo que pudiera provocar algún sentimiento de diferencia, por no hablar de conflicto, en el 'nosotros'... Lo que distingue a esta mítica pertenencia a una comunidad es que las personas sienten pertenencia y pueden compartir todo, porque son iguales' (Citado en Bauman, 2009, p. 191).

\section{El espacio escolar como discontinuidad: el aquí que habilita futuros.}

Aquí nos interesa analizar otros modos de construcción de la convivencia en los que el espacio escolar se instituye como espacio diferencial respecto del 'afuera'. Un espacio escolar que presenta discontinuidades con el afuera, habilitando otras miradas sobre la convivencia y al mismo tiempo, construye continuidades con un afuera a futuro en tanto imagina a los sujetos en otros escenarios posibles.

No es nuestra pretensión contraponer modelos conflictivos y no conflictivos de convivencia sino analizar el modo en que el conflicto se produce en las normas, en lo que expresan y en los espacios en blanco.

En el caso de la escuela 02, la emergencia del proyecto de convivencia está relacionada con las falencias que presentaba la aplicación del régimen de disciplina dispuesto por el Reglamento General de 1943). Tanto en el reglamento de convivencia como en las voces de los/as entrevistados/as se destaca que la convivencia es una cuestión del conjunto de los actores escolares y no exclusivas del/de la director/a.

El sistema de convivencia instituido presenta algunos rasgos que se destacan respecto de las demás escuelas. El reglamento es el único que se define como 'reglamento de convivencia' y en el mismo se regula tanto a los/ as alumnos/as como a los/as docentes estipulando lo que pueden/no pueden y lo que deben/no deben. Por otra parte, las sanciones implican 'medidas convencionales' (amonestaciones, llamados de atención, etc.) y 'medidas no convencionales' (canje de amonestaciones, acciones reparadoras, etc.); se estipulan las trasgresiones que dan lugar a la aplicación de cada una y la gradualidad en el proceso.

Las normas de convivencia instituyen un espacio de discontinuidad con el afuera, que se percibe como inclusivo en tanto los conflictos encuentran eco en la escuela.

...toda la dinámica de la comunidad se termina trasladando aquí y todo el enfrentamiento del sábado en el boliche se termina trasladando aquí, entonces, hay enfrentamientos, hay discriminación por el grupo al que pertenecés, pero creo que ante toda esa situación, por lo menos lo que yo reconozco de la comunidad, este es el único espacio donde encuentran un ámbito para resolver de una manera distinta ese conflicto (Profesor - E02). 
La frontera que instala la escuela no se construye respecto de lo que debe quedar fuera de la escuela sino de aquellos elementos que la escuela puede ofertar como diferencia para traducir los códigos aprendidos en otros circuitos. En este sentido los/as adultos no se conforman con pensar que la realidad de los jóvenes que la transitan simplemente 'es', entienden que la escuela puede producir una diferencia incluso a partir de las diferencias.

Entonces hay como esta doble sensación, pero yo creo que si vos te ponés a pensar decís "no, acá se puede hacer cualquier cosa", es más, es la sensación de/ vos lo hablás en la comunidad y demás y existe eso, si? y yo te puedo garantizar que es la escuela donde mejor se convive, donde mejor se resuelven los conflictos, sin embargo está esta sensación (Profesor - E02).

Distintos actores escolares asocian esta 'doble sensación' a los rasgos autoritarios de la localidad, que ve en esta forma de convivencia -en la que las sanciones no son el elemento más visible- una lógica permisiva en la que cualquier conducta es posible. Por esto, la 'diferencia' que produce la escuela es -según los/as entrevistados/as- muy resistida por la comunidad.

Con respecto a la vestimenta, en el reglamento se establece en sus normas que "los alumnos pueden venir vestidos como quieran, que permita trabajar adecuadamente en clase (respetando las reglas específicas para Taller y Laboratorio)". Las reglas del Taller y Laboratorio están vinculadas a las condiciones de seguridad en el trabajo de alumnos y alumnas, que son además normas que rigen en los ámbitos de trabajo técnicos.

Algunas de las problemáticas que veíamos emerger respecto de la vestimenta, se tramitan aquí de un modo muy distinto. Existe, entre otros, un fuerte trabajo respecto del género que se traduce en un proyecto de educación sexual, en el que se trabaja el tema de un modo amplio -desde los estereotipos de género hasta las diversas formas de violencia-, que se presenta formalmente, amparada en la ley provincial 2222 (Salud Sexual y Reproductiva). Esto plantea una discontinuidad con la identidad tradicional de la escuela técnica ligada a lo masculino y una discontinuidad con la localidad, definida por los/as entrevistados/as como un espacio signado por los estereotipos de género que los sujetos ligan a la fuerte presencia que el ejército ha tenido en el desarrollo de la localidad (10).

Esta escuela no está exenta de problemáticas -incluso las mismas que aquejan a otras- pero las transforma en conflictos políticos, desatando los nudos entre significante y significado, dando cuenta de la contingencia de esas ataduras: norma no es igual a autoritarismo; una presencia menos visible de la sanción no es igual a laissez faire; lo técnico no es igual a lo masculino.

El hecho de constituirse en sujetos de derecho es un aprendizaje en el que las normas tienen mucho que ver y por lo tanto, los adultos entienden que su tarea tiene una potencia y produce formas de subjetivación. Los sujetos de 
derecho, no se entienden aquí a través sólo de los derechos que poseen sino de la capacidad de cuestionamiento que se les habilita:

Yo, el otro día me pasó algo, que estábamos a la mañana con la bandera y yo estaba con las manos en los bolsillos y después, que se yo, terminó el izamiento de la bandera y dos pibas me golpearon la puerta acá y me dicen 'estuviste con las manos en los bolsillos en el izamiento de la bandera'. Para mí es una pavada pero te quiero decir que han podido venir a decirlo y para mí eso...ellas sienten que pueden decir algo y que por ahí no van a tener represalias por lo que dicen y esto creo que ha sido fruto de la convivencia, del hecho de que los pibes ven que hay cosas que son parejas para todos (Director - E02).

Esta capacidad de cuestionamiento está presente en la construcción de contratos pedagógicos áulicos, cuyo proceso es claro para los/as alumnos/as y habilita la negociación, la defensa de los derechos y el cumplimiento de los acuerdos. Además, esta es la única escuela en la que la Ley 2302 está incorporada a los principios y regulaciones que se establecen en el reglamento.

Entendemos que ni ésta ni las demás formas de entender la convivencia determinan la realidad de las escuelas sino que, en su traducción cotidiana, las normas adquieren matices diversos. Sin embargo, sostenemos que el modo de entender la posibilidad, la habilita.

En este sentido, el análisis de las normas como productoras de fronteras es central para comprender el modo en que las escuelas habilitan posibilidades ancladas o posibilidades desterritorializadas, entendiendo que no todas las discontinuidades representan la misma posibilidad respecto de la inserción presente y futura en el 'afuera'. El espacio escolar como espacio diferencial puede operar inhabilitando 'otras inserciones', cuando la distinción que produce se entiende como un fin en sí mismo, cuando sólo implica un pasaporte para ser parte de 'ese' espacio.

\section{Algunos cierres no suturados.}

Como hemos visto, algunas escuelas, distintas en sus rasgos más salientes, presentan continuidades en las formas de construir el espacio escolar a partir de las normas. Así, vemos emerger nuevas formas de 'comunidad' que reeditan encuentros en la homogeneidad. Sin embargo, a diferencia del modo en que el sistema educativo moderno intentó responder a la pregunta por lo común, aquí la homogeneidad opera despojada de la ficción de igualdad (Duschatzky \& Corea 2002) que implicaba promesa de inserción en el futuro.

Entendemos que estas nuevas formas de clausura -algunas sostenidas sobre una fuerte regulación explícita, otras sobre la des-regulación- pueden producir unos anclajes en la escuela, como espacio de 'lo conocido', de 'los iguales' como equivalentes, que no permiten inserciones en otros espacios y a futuro. 
Aquí la escuela opera como una comunidad pero no en el sentido de un 'Nosotros' que se constituye articulando las diferencias en torno a algunos elementos comunes, sino, lisa y llanamente como una comunidad de 'iguales', que se eligieron libremente los unos a los otros. Bauman (2009) analiza la nueva fisonomía que adopta la comunidad como una estrategia de autoprotección: '...la visión de comunidad es como una isla de cálida y doméstica tranquilidad en medio de un mar inhóspito y turbulento' (p. 193).

Sostenemos la posibilidad de que la escuela se configure como un espacio diferencial en el sentido de ofertar sentidos distintos de aquellos que habitan los sujetos en su cotidianeidad familiar, barrial e incluso social. Esta discontinuidad puede producir interpelación de 'lo familiar', 'conocido', 'cotidiano' pero puede también anclar a los sujetos a una nueva cotidianeidad y familiaridad que no ofrezca herramientas para trasponer sus bordes.

Por el contrario, existen construcciones normativas que ofrecen fronteras pero también algunos pasos fronterizos, ofrecen anclajes en un 'ser parte' que implica resguardo pero también habilitan la potencialidad de subversión presente en todo ordenamiento entendido como contingente.

\section{Notas Bibliográficas}

(1) No todos los reglamentos remiten estrictamente a la temática de la convivencia. Se abordan entrevistas a un directivo por escuela, dos profesores dos y dos alumnos. Las encuestas son un total de 30 por escuela realizadas en el anteúltimo año $\left(4^{\circ} \circ 5^{\circ}\right.$ dependiendo la modalidad).

(2) El trabajo de campo se realizó en el marco de un proyecto mayor del cual participé ("Intersecciones entre desigualdad y educación media..."- PAV 180). El mismo se llevó a cabo, desde 2005 a 2007, en Salta, Buenos Aires, ciudad de Buenos Aires y Neuquén, donde se seleccionaron seis escuelas en base a diversos criterios (ubicación, modalidad, tipo de gestión, etc.). Las escuelas de Neuquén constituyen nuestra muestra de estudio:

\begin{tabular}{|c|c|l|c|c|}
\hline & $\mathbf{N}^{\circ}$ & \multicolumn{1}{|c|}{ Tipo de Gestión } & Modalidad & Ubicación \\
\hline 01 & Pública & Técnica & $\begin{array}{c}\text { Localidad del interior - } \\
\text { enclave petrolero }\end{array}$ \\
\cline { 2 - 5 } & 02 & Pública & Técnica & $\begin{array}{c}\text { Localidad pequeña de } \\
\text { la zona cordillerana }\end{array}$ \\
\cline { 2 - 5 } & 03 & Pública, de gestión privada* & Bachiller & Ciudad de Neuquén \\
\hline \multirow{己}{山}{04} & Pública & Perito Mercantil & $\begin{array}{c}\text { Localidad del interior de la provincia, } \\
\text { de producción vitivinícola. }\end{array}$ \\
\hline 05 & Pública & Perito Mercantil & Ciudad de Neuquén \\
\hline 06 & Pública, de gestión privada* & Bachiller & Ciudad de Neuquén \\
\hline
\end{tabular}

* En la provincia de Neuquén la mayor parte del mercado privado de educación está compuesto por este tipo de escuelas. Son de gestión privada pero reciben subsidios estatales para el pago de los sueldos docentes. 
(3) Esta tradición articula la presencia de organismos de derechos humanos, encabezados por el obispo Don Jaime de Nevares, las reivindicaciones de clase en las puebladas de Cutral Có y Plaza Huincul y las grandes huelgas docentes, protagonizadas por ATEN en los años '90 (Ver Aiczinzon, 2005 y Favaro, luorno, \& Cao, 2006), profundizándose, en la última década las reivindicaciones sobre género y sexualidad producto del intenso accionar de grupos feministas (Bonaccorsi \& Reybet, 2008).

(4) Asociación de Trabajadores de la Educación de Neuquén.

(5) En el año 2006, los planes de estudio en vigencia sumaban aproximadamente 66.

(6) Por la suspensión de la Ley Federal de Educación, debido al fuerte rechazo del gremio docente y de distintos sectores de la comunidad educativa, el sistema educativo conserve su antigua estructura.

(7) También ha existido rechazo respecto a la Ley Nacional de Educación.

(8) Uno de los títulos que otorga esta escuela es de Técnico Químico.

(9) Esta norma aparece de forma manuscrita en el reglamento, como un agregado posterior a su elaboración.

(10) Denominación de los colegios con orientación Bachiller o Perito Mercantil.

(11) Esta es la primera localidad fundada en la provincia, en torno a uno de los fortines instalados en la 'Conquista del Desierto'.

\section{Referencias Bibliográficas}

- $\quad$ Aiziczon, F. (2005). Neuquén como campo de protesta. En Favaro, O. (comp.). Sujetos sociales y políticas. Historia reciente de la Norpatagonia Argentina. Neuquén: CEHEPYC, Universidad Nacional del Comahue.

- Favaro, O., luorno, G. \& Cao, H. (2006). Política y protesta social en las provincias argentinas. En Caetano, G. (comp.). Sujetos sociales y nuevas formas de protesta en la historia reciente de América Latina (pp. 93-141). Buenos Aires: CLACSO.

- Antelo, E. (2007). Variaciones sobre el espacio escolar. En Baquero, R., Diker, G. \& Frigerio, G. (comps.) Las formas de lo escolar (pp. 59-76). Buenos Aires: Del Estante Editorial.

- $\quad$ Bauman, Z. (2009). Modernidad Líquida. $1^{\mathrm{a}}$ edn., 10 $10^{\mathrm{a}}$ reimp. Buenos Aires: Fondo de Cultura Económica.

- Debattista, S. (2004). Educación y memoria: políticas educativas, políticas de la memoria en Neuquén: 1984/1998. En Rafart, G., Quintar, J. y Camino Vela, F. (comps.). 20 años de democracia en Río Negro y Neuquén. Neuquén: Educo.

- Dussel, I. (2003). La gramática escolar de la escuela argentina: un análisis desde la historia de los guardapolvos'. Anuario de Historia de la Educación. Buenos Aires: Prometeo.

- Dussel, I. (2005). ¿Se renueva el orden disciplinario escolar? Una lectura de reglamentos de convivencia en la Argentina de la Post Crisis. Revista Mexicana de Investigación Educativa, 10 (027), 1109-1121.

- Duschatzky, S. y Birgin A. (comp.) (2007). ¿Dónde está la escuela? Ensayos sobre la gestión institucional en tiempos de turbulencia. Buenos Aires: FLACSO Manantial.

- Duschatzky, S. y Corea, C. (2002). Chicos en banda. Los caminos de la subjetividad en el declive de las instituciones. Buenos Aires: UEPC /FLACSO / UNICEF / Paidós.

- Grinberg, S. (2008), Educación y poder en el siglo XXI. Gubernamentalidad y pedagogía en las sociedades de gerenciamiento. Buenos Aires: Miño y Dávila. 
- Kessler, G. y Goldberg, L. (2000). Cohesión social y violencia urbana. Un estudio exploratorio sobre la Argentina a fines de los 90. Buenos Aires. Mimeo.

- Kriger, M. (2010). Jóvenes de escarapelas tomar. Escolaridad, comprensión histórica y formación política en la Argentina contemporánea. La Plata: Observatorio de Jóvenes, Comunicación y Medios y Facultad de Periodismo y Comunicación Social, Universidad Nacional de La Plata.

- $\quad$ Laclau, E. (1990). New reflections on the revolution of our time. Londres: Verso.

- Laclau, E. y Mouffe, C. (2004). Hegemonía y estrategia socialista. Hacia una radicalización de la democracia. $2^{a}$ edn en español. Buenos Aires: Fondo de Cultura Económica.

- $\quad$ Litichever, L., Machado, L., Núñez, P., Roldan, A. \& Stagno, L. (2008). Nuevas y viejas regulaciones: Un análisis de los reglamentos de convivencia en la escuela. Revista Última Década, 15 (28), 93-121.

- Lizárraga, F. (2008). Jorge Omar Sobisch: ocho años de retórica reaccionaria. Trabajo presentado en las Terceras Jornadas de Historia de la Patagonia, San Carlos de Bariloche, 6-8 de noviembre.

- Mouffe, C. (2007). En torno a lo político. Buenos Aires: Fondo de Cultura Económica.

- Ortiz, R. (1998). Otro territorio. Ensayos sobre el mundo contemporáneo. $2^{\mathrm{a}}$ edn. Santa Fe de Bogotá: Convenio Andrés Bello. 